\title{
Perspectives on Politics Editors' Report 2017
}

\author{
Michael Bernhard, Editor in Chief \\ Daniel O'Neill, Associate Editor and Book Review Editor \\ Jennifer Boylan, Managing Editor
}

\section{INTRODUCTION}

We report here on the journal's operations from January 1, 2017 to December 31, 2017. This includes the final six months of Perspectives at Indiana University and its move to the University of Florida (UF) on June 1, 2017. We concentrate on the latter. This report covers the transition from Indiana to Florida, the editorial and technical innovations introduced by the UF editorial team, and reports summary statistics on submissions, editorial decision making, impact, and book review commissions, comparing the tenure of the UF team to the recent past.

\section{TRANSITION TO THE UNIVERSITY OF FLORIDA}

The editing of Perspectives on Politics at the University of Florida commenced on June 1 , 2017. The transition was complicated by the fact that the incoming editor in chief, Michael Bernhard, ruptured his quadriceps tendon in early May on a trip overseas and underwent reparative surgery only on May 15, 2017. He was thus unable to attend the orientation meeting planned by Cambridge University Press in New York. The slack was taken up by associate editor Daniel O'Neill and managing editor Jennifer Boylan, and the success of the transition was attributable in no small part to the extra effort they put in during this period.

Despite this mishap, the team managed to put the full infrastructure (office space, web interface, staffing, and training) for the editors and six editorial assistants in place on time on June 1. Substantial support in accomplishing this was provided by Cambridge University Press, APSA, and the outgoing team at Indiana University. Barbara Walthall, Jeffrey Isaac, and Mark Zadrozny and their staffs went out of their way to answer our questions, provide insight, and expedite the transfer.

The first task upon taking responsibility for the journal was to complete the editorial and production process for issue 15(3) which had been assembled and put into production by Indiana. This was useful in teaching the staff their responsibilities in the production process. The team met this challenge.
Indiana thankfully left us with a cushion of accepted material to publish both on the article and book review sides. However, as expected, there was also a substantial backlog on both sides that needed to be cleared out. In its last month, Indiana shipped us several hundred books and these had to be organized and prepared for review. Furthermore, within Editorial Manager we needed to familiarize ourselves and process articles under review and process the few dozen new manuscripts which Indiana did not process during their last month, as they were turning the journal over to us. While very time consuming, clearing the backlog allowed us to create and put in place our own procedures for the review of articles, editorial decision making, and the review of books.

\section{EDITORIAL INNOVATIONS \\ Reinforcement of Review Process Anonymity}

Upon taking control of the journal we were besieged by a large of number of inquiries and requests of the following nature:

"Would you be interested in an article on..."?

"Could you read over my manuscript and tell me if you would be interested in publishing it?"

"Would you please review my book? I can recommend the following readers...." "Iwould like to review____ 's book, entitled...."

"I would like to do a review essay of the following books: [...]. Would it be possible to have them sent to me?"

With regard to articles we felt that such requests could influence the fairness of the review process, by undermining the double blind nature of the editorial decision on whether to proceed to external review or reject submissions without external review. With regard to book reviews, we felt that requests could undermine the impartiality of the reviewer selections process (either in a positive or negative direction). As a result of this flood of requests, we introduced new language on the website, to reduce attempts to influence the review process and to combat any perception that such influence was possible:

The Editorial Team at Perspectives on Politics uses a double-blind review process for all manuscripts. Please do not email the Editors with information about your manuscript asking if you should submit your manuscript for review, as this 'un-blinds' the manuscript review process. General inquiries may be directed to the Managing Editor, Jennifer Boylan, at perspectives@apsanet.org.

The editorial Team at Perspectives does not entertain suggestions or proposals for book reviews. Book reviews are designed and assigned by the editorial staff. If you would like to have your book considered for review, please request your publisher to send a copy of your book to the address listed below. ${ }^{1}$

\section{Thematics}

One of the consistent features of Perspectives on Politics is the publication of clusters of thematically related articles together in one issue. For instance, issue 15(2), the last fully produced by Indiana, was devoted to the study of post-communist politics. In our estimation, these periodic theme-focused issues and sections are one of the unique and innovative features of the journal. In the past, they have emerged in a more haphazard fashion, on the basis of what comes across the Editorial Manager transom, and then finding ways to connect them. We have continued to do this. The first issue that we produced on our own, 15(4), brought together a series of articles which all addressed "Problems of the State in the Developing World.” In 16(1) we have an extensive special section on "The Politics of Inclusion and Exclusion.” In issue 16(2) we will be clustering a series of articles on the new contentiousness of American politics. And finally, later this year, if work in the editorial queue is finished in time, we hope to do a special section on "Cyberpolitics."

While we feel we have been quite fortunate to have these clusters emerge naturally, we have taken a more proactive stance to cultivate groups of articles on emerging and highly relevant themes through calls for papers. To date we have issued two calls. ${ }^{2}$ 


\begin{tabular}{lrr} 
Table 1 & & \\
PoP Manuscript Submissions per Year & & \\
Time Period & New Manuscripts & Revised Manuscripts \\
\hline $06 / 01 / 17-01 / 09 / 2018$ & 180 & 50 \\
\hline $01 / 01 / 2017-05 / 31 / 17$ & 106 & 30 \\
\hline 2016 & 321 & 51 \\
\hline 2015 & 258 & 53 \\
\hline 2014 & 253 & 47 \\
\hline 2013 & 204 & 43 \\
\hline
\end{tabular}

Table 2

PoP Manuscript Submissions by Location of Corresponding Author

\begin{tabular}{lrr} 
Time Period & Within the US & Outside of the US \\
\hline $06 / 01 / 17-01 / 09 / 2018$ & $102(56.4 \%)$ & $79(43.6 \%)$ \\
\hline $01 / 01 / 2017-05 / 31 / 17$ & $58(56.9 \%)$ & $44(43.1 \%)$ \\
\hline 2016 & $190(59.9 \%)$ & $127(40.1 \%)$ \\
\hline 2015 & $155(60.8 \%)$ & $100(39.2 \%)$ \\
\hline 2014 & $170(67.5 \%)$ & $82(32.5 \%)$ \\
\hline 2013 & $140(69.0 \%)$ & $63(31.0 \%)$ \\
\hline
\end{tabular}

Table 3

Average Number of Days in Review Process

\begin{tabular}{lrr} 
Time Period & Submission to Editor Assignment & Submission to First Decision \\
\hline $06 / 01 / 17-01 / 09 / 2018$ & 0.7 & 32.2 \\
\hline $01 / 01 / 2017-05 / 31 / 17$ & 12.4 & 56.4 \\
\hline 2016 & 6.9 & 42.1 \\
\hline 2015 & 6.3 & 45.9 \\
\hline 2014 & 6 & 51.8 \\
\hline 2013 & 5.3 & 44 \\
\hline
\end{tabular}

One of the ways we have tried to cultivate such calls is to encourage board members to propose them and take part in the editorial process as guest editors. The first foray of this kind was proposed by professor Samantha Majic on the "Politics of Celebrity." Togetherwe issued a call for papers and enlisted Professor Majic to act as guest editor on the section. To date we have received two submissions and have not accepted any articles. More ambitiously, we have issued a call for a full issue on "The Trump Presidency: Causes and Consequences." We have already received several submissions and some are under active review.

\section{Transparency}

Perspectives was one of the major journals not to sign the Journal Editors' Transparency Statement (JETS). While the former editor and the board were highly supportive of research transparency and replicability (where appropriate), there was extensive concern over whether DA-RT and JETS had a onesize-fits-all notion of research and how to implement transparency. 3

The present editorial staff shares these concerns, and is interested in promoting data transparency and the replicability of work where it is appropriate.
To this end, the first of our innovations has been working with Cambridge to create a Perspectives on Politics Dataverse. It should be up and running for issue 16(1). Given that the norm of posting replication data and dofiles for quantitative work is widespread and has broad support in the discipline, we are now requiring quantitative publications in the journal to post a replication package to the Dataverse.

With regards to qualitative work we are being more cautious in terms of implementing universal standards for data and inferential transparency. We are actively working with individual scholars to cultivate new ways of doing this, and are encouraging them to use online appendices, so as not to crowd out substantive content in the body of the journal itself. There are qualitative articles in the pipeline which will make use of the Syracuse Qualitative Data Repository and we are poised with an article that is currently under "minor revision" to do a pilot experiment with active citation.

We are also in the process of studying the replication and transparency statements of other major journals so as to update the online "Statement on Scholarly Recognition."4

In this regard we find the policies recently implemented by the American Political Science Review to be flexible, pragmatic and tolerant and we are thinking through what, if anything, Perspectives needs or wants to add to them to better serve the membership, and the part of the discipline which reads and supports the journal.

\section{TECHNICAL INNOVATIONS \\ Front-End Manuscripts}

We easily adapted to the Editorial Manager submission, processing, and review systems for manuscripts. We did, however, implement a couple of technical innovations in this regard. First, and most significantly, we have begun to experiment with publishing manuscripts on FirstView, and to date five items have appeared in this format. This has often been at the behest of authors looking to publicize their work. It has also been initiated by us for standalone pieces which we think will draw broad public attention (such as David Lake's presidential address). Second, in January we activated Publons, an online app that credits reviewers for their service. We hope that such recognition allows those who shoulder a heavy disciplinary service burden through review to document their records for their colleagues and employers. 


\section{Book Review Section}

At Indiana, book reviews were commissioned and processed using an email system. At the request of APSA and Cambridge University Press we moved the book review commissioning, submission, and production process into Editorial Manager. This required close cooperation with Cambridge to develop an effective workflow system that included several discrete processes:

1. the creation of an assignment file;

2. sending invitation letters to individuals asking them to review books;

3. sending commission letters once an individual agrees to a review, outlining the requirements and format of the review;

4. setting up a system of reminder letters sent to individuals who are late to respond to the original invitation or who are late to send in their book review;

5. collecting author drafts as Editorial Manager submissions;

6. working with authors to edit the manuscripts;

7. setting up a system for handling copyright transfer; and

8. transferring final drafts to Cambridge for production.

\section{Production}

Under the leadership of managing editor Jennifer Boylan, our team has worked hard to move the publication schedule closer to on-time, and we have made significant improvements in this regard. The online publication of issues 15(1) and 15(2), both published before our tenure, occurred about four weeks after the scheduled online publication date. The first issue that we managed, 15(3), published online 10 days after the scheduled date, while the second issue we managed, 15(4), published online eight days after the scheduled date. Issue 16(1) is currently on schedule to publish on time and we intend to continue to improve the production processes in order to consistently publish on time. The improvement in the meeting of these deadlines is largely due to a number of innovations to the proofing and revision process which diminish the need for repeated proofing, particularly for book reviews. In addition, we have stopped holding manuscripts for each issue and submitting them as a package. We now send manuscripts to Cambridge for production as soon as we have scheduled them for publication in a specific issue.
We have also worked carefully with Cambridge University Press to try to hit the page budget for each issue. Issues 15(1)-15(3) were an average of 18 pages over the page budget. To hit the annual target limits we printed Issue 15(4) slightly under the page budget. Estimates for the 16(1) page count put us very close to the 296 budgeted editorial pages.

\section{Other Innovations}

We have increased Perspectives on Politics' activity on Twitter, resulting in a $20 \%$ increase in followers since August 2017. We are in the process of reviewing and synchronizing the Cambridge Core and APSA websites, and updating and editing the text and pdf links with regard to submission, formatting, and scholarly recognition. We have cleaned up Editorial Manager, including withdrawing "zombie submissions" (submissions abandoned by authors, duplicate files) and moved submissions already published but remaining in the EM workflow process out of EM working folders.

\section{SUBMISSIONS AND PROCESSING Number of Submissions}

In 2017 we received 296 new manuscripts, and 80 revised manuscripts. Of these, 180 new and 50 revised were processed by the UF team. The total is somewhat less than the high of 321 received in 2016. However this is up substantially from previous years (see table 1). We suspect that the difference

\section{Table 4}

\section{Editorial Decisions by the UF Team}

\begin{tabular}{lrrr} 
Editor Decision & Total Decisions & Frequency of Decision & Average Days to Decision \\
\hline Decline, No External Review & 118 & $62.8 \%$ & 17.3 \\
\hline Decline, After External Review & 44 & $23.4 \%$ & 83.2 \\
\hline Major Revision & 24 & $12.8 \%$ & 108.4 \\
\hline Minor Revision & 2 & $1.1 \%$ & 126 \\
\hline Total Editor Decisions & 188 & $100 \%$ & 45.5
\end{tabular}

\section{Table 5}

Outcome of 1st Round of the Review Process (percentage)

\begin{tabular}{lrrrrrr} 
Manuscript Decision & $\mathbf{6 / 1 / 1 7 - 1 / 9 / 1 8}$ & $\mathbf{1 / 1 / 1 7 - 5 / 3 1 / 1 7}$ & $\mathbf{2 0 1 6}$ & $\mathbf{2 0 1 5}$ & $\mathbf{2 0 1 4}$ & $\mathbf{2 0 1 3}$ \\
\hline Decline, No External Review & 62.8 & 53.5 & 69.1 & 69.6 & 64.9 & 56.7 \\
\hline Decline After Ext. Review & 23.4 & 31.7 & 22.3 & 19.2 & 22.9 & 21.4 \\
\hline Major Revision & 12.8 & 6.9 & 5.5 & 7.2 & 7.4 & 8.1 \\
\hline Minor Revision & 1.1 & 3 & 2.8 & 4 & 3.9 & 3.3 \\
\hline Conditional Accept & 0 & 0 & 0.3 & 0 & 0.4 & 0.5 \\
\hline Accept & 0 & 5 & 0 & 0 & 0.4 & 0.5
\end{tabular}

Table 6

\section{Journal Impact 2012-2016}

\begin{tabular}{lrrr} 
Year & Impact Factor & 5-year Impact Factor & Rank within Political Science \\
\hline 2016 & 3.234 & 3.680 & $8 / 165$ \\
\hline 2015 & 2.462 & 3.257 & $10 / 163$ \\
\hline 2014 & 2.132 & 2.661 & $11 / 161$ \\
\hline 2013 & 3.035 & 2.628 & $2 / 157$ \\
\hline 2012 & 1.963 & $n / a$ & $10 / 157$ \\
\hline
\end{tabular}


between the first and second halves of 2017 is due to author reticence to submit manuscripts to an outgoing editorial team and optimism about prospects for publication under a new editorial team.

APSA flagship journals not only play an important role in the discipline domestically; they are publications of international importance. One of our stated goals is to further internationalize the authorship base and audience. Table 2 shows the increasing rate of submissions from authors based in countries other than the United States. It is now consistently over $40 \%$ and peaked in the second half of 2017 at $43.6 \%$.

\section{Processing of Submissions}

One of our goals upon assuming editorship of the journal was to maintain its record of prompt and professional review of manuscripts. Perspectives invites, at minimum, four reviewers on the first round for articles. If we receive two recommendations of rejection before all reviews are in, we terminate the process early. An acceptance on the first round is exceptionally rare, and has not happened since we began to edit the journal. Many manuscripts go through the revise and resubmit stage twice. On subsequent rounds, all four initial reviewers are often willing to read the revisions. When they are not, we try to avoid adding new reviewers, and only do so when the number of reviewers reading the revisions falls below two. Because of the stringent nature of peer review at the

journal and the large number of reviewers, we work hard to be efficient and stay on top of manuscripts. The results of those efforts are visible in the statistics presented in table 3.

As is apparent in table 3 , the time to editor assignment and first decision has been substantially condensed since we began to edit the journal on June 1, 2017.

\section{Editorial Decisions}

Table 4 summarizes the editorial decisions taken since we assumed editorial responsibilities. As in the past the majority of manuscripts are rejected without external review. Generally speaking these submissions were not appropriate to the journal either because they were not academic political science papers, were too specialized for a general interest, public-sphere focused journal like Perspectives, or were of poor quality. Of the 70 submissions that went out for external review, over $60 \%$ were subsequently rejected. The remainder were given a chance to revise and resubmit their manuscripts. The overwhelming number of these decisions asked for major revisions. No manuscript has been accepted without at least minor revision under our stewardship.

The vast majority of manuscripts given a revision decision under our editorship have been published. To date, 18 have found their way to print or the production queue. Three were rejected after the first round of revision when reviewers returned harsh verdicts. The remaining five are back with the authors or

Table 7

\section{Reviewer Invitations}

\begin{tabular}{lrr} 
& Accepted Invitation (\%) & Declined Invitation (\%) \\
\hline Front-End & $429(59.2 \%)$ & $296(40.8 \%)$ \\
\hline Book Review-End & $251(36.5 \%)$ & $436(63.5 \%)$ \\
\hline
\end{tabular}

Table 8

Book Reviews Commissioned:

June 1, 2017-January 9, 2018

\begin{tabular}{lrrrrrr} 
Field & Single BR & Double BR & Triple BR & Review Essay & Critical Dialogue & Total Reviews \\
\hline IR & 36 & 2 & - & - & 8 & 56 \\
\hline American & 40 & 13 & - & 2 & 4 & 78 \\
\hline Theory & 49 & 3 & 1 & 1 & 5 & 71 \\
\hline CP & 34 & 9 & 1 & 2 & 4 & 69 \\
\hline Total & 159 & 27 & 2 & 5 & 21 & 274 \\
\hline
\end{tabular}


sends a signal to the discipline. A review in the journal is a mark of the significance of a newly published book and the review itself can serve as an important bit of evidence of impact and in promotion and tenure decisions. The review mission is not a sideline of the journal, but a central function, of equal importance to the publication of articles. Lining up reviewers is an onerous task that involves persistence due to a large number of rejections of invitations. Table 7 compares the rate of rejection for book review invitations to that of article review rejections on the front end. While only $40 \%$ of article review requests were turned down in the last six months, over $60 \%$ of book review requests are rebuffed. This necessitates multiple invitations, often several.

Table 8 shows the book reviews that the UF team has commissioned since we assumed responsibility for the journal. These include conventional book reviews (single, double, and triple), review essays (multiple books reviewed by a single author in a more extended format), critical dialogues (where two authors of related books review each other's work and respond to one another), and review symposia (where multiple authors review a book of potential import). These are broken down by field. The table includes both completed and forthcoming reviews.

To date we have commissioned 274 book reviews. Most volumes of the journal contain between 360 and 400 reviews (90-100 per issue). Thus we are ahead of the curve to hit our target for the first year. There is a slight imbalance now between IR and the other three fields. We are actively working to correct this as much as possible, but there seem to be fewer books in IR than the other fields.

\section{CONCLUSIONS}

The UF editorial team has successfully negotiated the transition and established a set of normal procedures for assuring the continuity and quality of the journal. We have also introduced a number of substantive and technical innovations that we hope will contribute to the continued success of the journal. We wish to express our thanks to APSA, Cambridge University Press, and our precursors at Indiana University for their support in this endeavor. Our experience has been both challenging and rewarding. We look forward to continuing to work for the welfare of the association and the discipline in the coming year.

\section{NOT E S}

1. http://apsanet.org/perspectivessubmissions

2. Both calls can be read in greater detail here https://cambridge.org/core/journals/perspectivesonpolitics/call-for-papers

3. We are unclear what replicability means in the context of interpretive work or what is implied with regard to data transparency for historical archival, ethnographic, or normative theoretical work. It is clear to us that standards need to be developed by the community of scholars who use these methods.

4. http://www.apsanet.org/LinkClick.aspx?fileticket $=\_0 s s K G v 37 e 0 \% 3 \mathrm{~d} \&$ portalid $=54$

5. Next year we will lose two of our most cited articles - Gillens and Page, and Geddes, Wright, and Franz. See https://cambridge.org/core/ journals/perspectives-on-politics/information/ perspectives-most-cited-articlessince-launch 